\title{
Estudo Prospectivo das Características Sonográficas no Diagnóstico de Nódulos Sólidos da Mama
}

\author{
Prospective Study of The Ultrasound Features in the Diagnosis of Solid Breast Lesions \\ Régis Resende Paulinelli, Célio da Silva Rocha Vidal, Alessandro Naldi Ruiz, \\ Vardeli Alves de Moraes, Júlio Roberto Macedo Bernardes Júnior, Ruffo de Freitas Júnior
}

\section{RESUMO}

Objetivo: avaliar, por meio de estudo prospectivo, o valor de diferentes características ultrasonográficas dos nódulos sólidos, na diferenciação de lesões malignas e benignas da mama. Métodos: foram incluidas 142 pacientes do Programa de Mastologia do Departamento de Ginecologia e Obstetrícia da Universidade Federal de Goiás com nódulos sólidos da mama. A ultra-sonografia mamária foi realizada pelo médico estagiário de mastologia, acompanhado do preceptor. As seis caracteristicas estudadas foram: contornos, ecos internos, ecos posteriores, diferença dos diâmetros, ligamentos de Cooper e halo ecogênico. Cada descrição característica ultra-sonográfica foi analisada estatisticamente e comparada, após a exérese da lesão, com o resultado do exame anatomopatológico.

Resultados: dentre as 142 pacientes incluidas no estudo, 90 (63\%) tiveram suas lesões ressecadas, com diagnóstico de 77 tumores benignos (86\%) e 13 de malignos (14\%). Foram significantes no diagnóstico de malignidade as seguintes características ultra-sonográficas: presença de sombra acústica posterior ( $p=0,0001)$, contornos irregulares ( $p=0,0007)$, ecos internos heterogêneos ( $p=0,0015)$ e diâmetro ântero-posterior (AP) maior que o látero-lateral $(L L)(p<0,0001)$. A presença de halo ecogênico no tumor e a visibilização dos ligamentos de Cooper espessados não influenciaram o diagnóstico de malignidade nesse estudo.

Conclusão: a ultra-sonografia é um método diagnóstico que pode ajudar na diferenciação de tumores sólidos benignos e malignos. Os contornos irregulares, os ecos internos heterogêneos, a sombra posterior e o diâmetro AP maior que o LL, quando presentes, apresentaram alta correlação com o exame anatomopatológico de câncer.

PALAVRAS-CHAVE: Mama: câncer. Mama: doenças benignas. Ultra-sonografia.

\section{Introdução}

O câncer de mama é doença de elevada incidência e mortalidade em todo o mundo, representando grave problema de saúde pública. Excetuando-se o câncer de pele, ele é o câncer mais freqüente em mulheres, sendo esperados 1,05 milhão de novos casos para o ano de 2000, correspondendo a $22 \%$ de todos os casos de câncer. É ainda o câncer de maior mortalidade em quase todos

Programa de Mastologia do Departamento de Ginecologia e Obstetrícia da Universidade Federal de Goiás

Correspondência: Ruffo de Freitas Júnior

Alameda das Rosas, 533 - Setor Oeste

74110-060 - Goiânia - GO

Tel/Fax: (62) 212-2049

e-mail: ruffo@medicina.ufg.br os países do mundo ${ }^{1}$. No Brasil, estimaram-se para 200131.590 casos novos e 8.670 óbitos decorrentes dessa neoplasia ${ }^{2}$.

Nas últimas cinco décadas, sua incidência vem aumentando anualmente 1,5 a $2 \%$ em todo o mundo, principalmente nas áreas de tradicional baixa incidência, como Japão e China ${ }^{1}$. Por outro lado, alguns países desenvolvidos já estão conseguindo reduções significativas em suas taxas de mortalidade por câncer de mama. Acredita-se que essa redução seja devida principalmente ao seu diagnóstico precoce e às novas opções terapêuticas ${ }^{1,3}$.

Com relação ao diagnóstico precoce das neoplasias mamárias, a popularização dos programas de rastreamento mamográfico tem recebido o maior destaque nos meios científicos. Em recente meta-análise com os oito maiores estudos 
randomizados, foi demonstrada uma redução média de $24 \%$ nas mortes por câncer de mama, em mulheres na pós-menopausa, e 18\% na pré-menopausa, com o uso da mamografia. Além da redução na mortalidade, o diagnóstico precoce pode permitir tratamentos menos mutilantes, com maior possibilidade de conservação mamária e com possibilidade de um resultado estético mais favorável ${ }^{3}$.

Do mesmo modo, uma grande expectativa foi gerada com relação à ultra-sonografia (USG) no diagnóstico de lesões mamárias. Desde a década de 70, vários foram os entusiastas da sua utilização no diagnóstico das doenças da mama ${ }^{4}$. Entretanto, os resultados práticos foram, até certo ponto, decepcionantes. Isso em parte decorreu devido à pouca experiência em sua utilização, ao uso de transdutores inadequados, de aparelhos de baixa qualidade e da sua incapacidade de detectar as microcalcificações suspeitas. Assim, por muito tempo essa técnica foi subvalorizada e até mesmo denegrida ${ }^{5}$.

A partir da década de 80, com o aparecimento de ecógrafos em tempo real e com a melhor resolução da imagem, a USG mamária vem assumindo um papel de destaque na propedêutica mamária. Além de apresentar a vantagem de ser um procedimento não invasivo e bem tolerado pelas pacientes, esse exame também pode trazer informações importantes complementares ao exame físico e à mamografia (em especial nos casos de mamas densas, nas quais as lesões nodulares podem passar despercebidas pela mamografia). A sua utilização como método de rastreamento permanece desacreditada, mas sua utilização como um método complementar, auxiliando no diagnóstico, já é indiscutivel ${ }^{5}$.

Principalmente a partir da década de 90, novos recursos sonográficos como aparelhos de maior resolução, o Doppler colorido, a mamotomia acoplada à USG, o aparecimento de contrastes especiais para a USG, os aparelhos com imagem tridimensional, sistemas computadorizados de detecção de lesões sonográficas, a avaliação sonográfica perioperatória das margens do tumor, entre outras novidades, têm sido promessa contínua de ampliação do uso da USG como método complementar de extrema importância dentro da mastologia ${ }^{6}$.

A diferenciação entre lesões sólidas e císticas é relativamente fácil à USG; entretanto, apesar dos avanços, a separação entre nódulos sólidos benignos e malignos ainda é controversa. Várias características sonográficas dos nódulos sólidos são citadas pelos autores como suspeitas de malignidade, mas as divergências são muitas e a real importância de cada uma dessas caracte- rísticas ainda deve ser fonte de investigação ${ }^{7,8}$.

No intuito de avaliar, por meio de um estudo prospectivo, o significado da USG na diferenciação de lesões mamárias sólidas benignas e malignas, e quais, dentre as características citadas pelos autores, têm real importância para o diagnóstico de malignidade, nos propusemos a desenvolver este trabalho.

\section{Pacientes e Métodos}

Foram incluídas no estudo 142 pacientes provenientes do Programa de Mastologia do Departamento de Ginecologia e Obstetrícia da Universidade Federal de Goiás, que estavam em investigação diagnóstica para nódulos sólidos da mama, entre maio de 1998 e abril de 2001. Não foram incluídas pacientes com cistos ou que apresentassem lesão sólida ulcerada e/ou com edema da pele sobrejacente.

A USG mamária foi utilizada como parte da avaliação para nódulos sólidos da mama, juntamente com a mamografia e a punção aspirativa por agulha fina. A ecografia foi realizada utilizando-se um aparelho TOCK-MED 20-20, ao qual era acoplado um transdutor linear de 7,5 MHz. Os exames foram feitos sempre pelo médico estagiário do Setor de Mastologia, acompanhado do preceptor.

Para a realização da USG a paciente era colocada em decúbito dorsal, mantendo os braços erguidos e as mãos atrás da cabeça. Utilizou-se gel especifico para complementar o contato entre a pele e o transdutor. As varreduras foram feitas seguindo o sentido horário, da periferia para o centro da mama. As características ultra-sonográficas estudadas em cada tumor foram: contornos (regulares ou irregulares), ecos internos (homogêneos ou heterogêneos), ecos posteriores (presença de sombra, presença de reforço [ou inalterado se alteravam]), halo ecogênico (presente ou ausente), ligamentos de Cooper (normais ou espessados) e orientação entre os diâmetros (diâmetro látero-lateral maior que o ântero-posterior ou vice-versa).

Todas as características acima descritas foram anotadas em ficha própria e arquivadas até a digitação dos dados.

Cada característica ultra-sonográfica foi comparada, após a exérese da lesão, com o resultado do exame anatomopatológico, mediante teste do $\chi^{2}$, sendo considerado significativo quando o $\mathrm{p}$ foi inferior a 0,05.

Antes do início da pesquisa, o projeto foi aprovado pelo Comitê de Ética em Pesquisa do Hospital das Clínicas da UFG, sendo respeitado o sigilo na identidade de cada paciente. 


\section{Resultados}

Dentre as 142 pacientes incluídas no estudo, $90(63 \%)$ tiveram suas lesões ressecadas, com diagnóstico de 77 (86\%) tumores benignos e 13 $(14 \%)$ malignos. A distribuição histológica das lesões ressecadas pode ser vista na Tabela 1. A média de idade para os tumores malignos foi de 48,6 anos e de 35,7 anos para os tumores benignos $(p=0,001)$. A média do tamanho do tumor foi semelhante entre os casos de câncer $(33,6 \mathrm{~mm}) \mathrm{e}$ os casos benignos $(27,0 \mathrm{~mm})(\mathrm{p}=0,09)$.

Tabela 1 - Diagnóstico histólogico dos nódulos sólidos ressecados.

\begin{tabular}{lrr}
\hline Diagnóstico histológico & $\mathbf{n}$ & $\%$ \\
\hline Fibroadenoma & 54 & 60,0 \\
Fibroadenose & 1 & 12,0 \\
Lipoma & 2 & 2,5 \\
Tumor filóides & 2 & 2,5 \\
Papiloma & 1 & 1,0 \\
Adenoma tubular & 1 & 1,0 \\
Adenose esclerosante & 1 & 1,0 \\
Outros benignos & 5 & 6,0 \\
Carcinoma ductal invasor & 10 & 11,0 \\
Carcinoma ductal in situ & 1 & 1,0 \\
Carcinoma lobular & 1 & 1,0 \\
Carcinoma medular & 1 & 1,0 \\
Total & 90 & 100 \\
\hline
\end{tabular}

Das 142 pacientes estudadas, 90 tiveram suas lesões ressecadas para estudo histológico.

As características ecográficas da lesão foram estudadas em relação ao diagnóstico de malignidade ou benignidade. A presença de contornos irregulares foi encontrada em 10 dos 13 casos de câncer e em 19 dos 77 casos de tumores benignos $(p=0,0007)$. Os ecos internos heterogêneos estavam presentes em oito casos malignos e em 13 benignos ( $p=0,0015)$. A sombra acústica posterior foi vista em 9 tumores malignos e em 11 benignos $(p=0,0001)$. Já o diâmetro ântero-posterior maior que o látero-lateral esteve presente em sete casos de câncer e em três benignos $(p=0,00001)$. A presença de halo ecogênico nos tumores malignos foi vista em três casos e em 11 benignos $(\mathrm{p}=0,7)$. A visualização dos ligamentos de Cooper espessados esteve presente em apenas um tumor maligno e em um benigno $(p=0,7)$. A análise das características ecográficas de acordo com a histologia mostrou que os contornos irregulares, ecos internos heterogêneos, sombra acústica posterior e o diâmetro ânteroposterior maior que o látero-lateral estiveram significativamente mais presentes nos tumores malignos. Os ligamentos de Cooper espessados e a presença de halo ecogênico não influenciaram o diagnóstico de malignidade, conforme pode ser observado na Tabela 2.

Tabela 2 - Análise das características ultra-sonográficas de acordo com o diagnóstico histológico.

\begin{tabular}{|c|c|c|c|c|}
\hline Características ecográficas & $\begin{array}{c}\text { Maligno } \\
n=13\end{array}$ & $\begin{array}{c}\text { Benigno } \\
\mathrm{n}=77\end{array}$ & $\chi^{2}$ & $p$ \\
\hline Contornos irregulares & $10(77 \%)$ & $19(25 \%)$ & 11,6 & 0,0007 \\
\hline Ecos internos heterogêneos & $8(62 \%)$ & $13(17 \%)$ & 10,0 & 0,0015 \\
\hline Sombra acústica posterior & $9(69 \%)$ & $11(14 \%)$ & 16,3 & 0,0001 \\
\hline Diâmetro AP>LL & $7(54 \%)$ & $3(4 \%)$ & 23,2 & 0,00001 \\
\hline Ligamentos de Cooper espessados & $1(8 \%)$ & $1(8 \%)$ & 0,18 & 0,7 \\
\hline Halo ecogênico anterior & $3(23 \%)$ & $11(14 \%)$ & 0,16 & 0,7 \\
\hline \multicolumn{5}{|c|}{$\begin{array}{l}\mathrm{n}=\text { número de casos; } \mathrm{AP}>\mathrm{LL} \text { = diâmetro ântero-posterior maior que o látero-lateral; } \\
\chi^{2}=\text { teste do qui-quadrado }\end{array}$} \\
\hline
\end{tabular}

A diferenciação entre nódulos císticos e sólidos, para lesões acima de $5 \mathrm{~mm}$, é notada com facilidade à USG. Com um pouco de experiência, é possivel avaliar a probabilidade de uma lesão ser um cisto atípico e não uma lesão sólida ${ }^{7}$.

Por muito tempo, muitas equipes limitaram a utilização da USG somente a esta distinção, indicando biópsias em todos os casos de nódulos só$\operatorname{lidos}^{7}$. Essa estratégia permite obter excelente sensibilidade, às custas de especificidade muito baixa, gerando várias biópsias cirúrgicas desnecessárias, com prejuízos econômicos, psicológicos e estéticos para as pacientes. Muitos médicos têm aderido a essa prática médica defensiva, com receio de não diagnosticar um caso de câncer e ser vítima dos processos médico-legais, cada vez mais freqüentes em nosso meio ${ }^{7}$.

Apesar de ainda existirem controvérsias, a maioria dos autores concorda que, com os equipamentos atuais, lesões sólidas com mais de $5 \mathrm{~mm}$ podem ser adequadamente avaliadas por ultrasonografista experiente. Várias características são apontadas como sendo importantes na diferenciação entre lesões benignas e malignas, porém a importância que cada autor atribui a cada uma das características está longe de ser uniforme. Michelin e Levy ${ }^{8}$, estudando prospectivamente 2.685 casos com diagnóstico histológico, consideraram a heterogeneidade dos ecos internos como 
o elemento mais importante no diagnóstico das lesões sólidas. Afirmaram ainda que $90 \%$ dos tumores malignos apresentam um ou mais dos seguintes sinais cardinais: contornos irregulares, bordas pouco nítidas, contraste mais nítido com o parênquima adjacente, além da já comentada heterogeneidade. Consideraram como secundários ou de menor importância as seguintes características: atenuação acústica posterior (presente em $20 \%$ a $60 \%$ dos cânceres, mas pouco freqüente em tumores menores que $2 \mathrm{~cm}$ ), espessamento ou retração da pele espessamento dos ligamentos de Cooper, distorção arquitetural adjacente ao nódulo, dissociação volumétrica em relação à mamografia ou ao exame clínico (tamanho menor da lesão à USG), diâmetro ântero-posterior maior que o látero-lateral, halo hiperecogênico anterior e extensões hipoecogênicas (ramificações da lesão).

Stavros et al. ${ }^{9}$, propuseram como critérios de malignidade: espiculações, contornos irregulares, contraste elevado, atenuação posterior, visibilidade de calcificações, extensão ductal, aspecto ramificado e microlobulações na superficie do nódulo. Estes mesmos autores encontraram para o método, no caso de haver uma ou mais características suspeitas na lesão, sensibilidade de $98,4 \%$, especificidade de $72,9 \%$, valor preditivo positivo de $38 \%$ e valor preditivo negativo de $99,5 \%{ }^{9}$.

Huber et al. ${ }^{10}$, estudando 77 lesões circunscritas, consideraram como mais importantes: a presença de contornos irregulares, distorção arquitetural, aderência à pele ou à parede posterior ou nódulo não móvel.

Durfee et al. ${ }^{11}$, em um estudo retrospectivo com 298 lesões malignas palpáveis, encontraram $38(12,8 \%)$ tumores sem expressão mamográfica, aparecendo apenas à USG. As características mais comuns dos nódulos, relatadas nos laudos, foram: contornos irregulares $(72 \%)$, lesões lobuladas (16\%) e lesões circunscritas (12\%).

No trabalho aqui apresentado, procuramos escolher para a análise as características mais conhecidas e mais facilmente observadas pelo ultra-sonografista durante um exame mamário, e observar qual a importância de cada uma das características. Dentre os elementos analisados, encontramos chance maior de malignidade quando qualquer uma destas características for positiva: sombra acústica posterior, contornos irregulares, ecos internos heterogêneos e diâmetro ântero-posterior maior do que o látero-lateral. $\mathrm{O}$ achado de halo ecogênico anterior ao tumor e o espessamento dos ligamentos de Cooper não tiveram importância na nossa análise, o primeiro provavelmente pela subjetividade da sua identificação durante o exame e o segundo, devido a sua baixa ocorrência.

Quando qualquer uma das características ligadas ao câncer foi encontrada durante o exame, o risco foi consideravelmente alto para justificar uma confirmação histológica da lesão $(28,2 \%$ de malignidade associada). Por outro lado, é importante lembrar que, no presente estudo, dois casos de câncer $(15,4 \%)$ não apresentavam nenhuma das características sugestivas de malignidade. Assim, deve-se considerar que o aspecto de benignidade à USG, como fator isolado, não exclui a possibilidade de biópsia confirmatória, ou mesmo seguimento com intervalo mais curto. Nesses casos, outros elementos, como a idade da paciente, podem vir a ser decisivos.

Alguns novos recursos ligados à USG mamária vêm sendo testados. Kitaoka et al. ${ }^{12}$ utilizaram, para ajudar na diferenciação entre lesões benignas e malignas, um histograma dos ecos internos da USG, em que a média do centro de gravidade e o raio entre as bordas inferiores e superiores da lesão foram comparados como parâmetros, encontrando significância estatística. Já Rosen e Soo $^{13}$ encontraram vantagem em se utilizar aparelho de USG especial que contém o recurso de imagem harmônica dos tecidos (Tissue harmonic imaging sonography-THI), quando comparado ao método tradicional. Quanto ao recurso do Doppler colorido aplicado à USG mamária, apesar de ter sido sugerido por alguns autores, esse recurso tem trazido pouco ganho adicional na acurácia da USG convencional, para a diferenciação das lesões mamárias sólidas ${ }^{14}$. Existem ainda tentativas de usar métodos de análise da imagem da USG computadorizados, uso de contrastes para USG, entre outras novidades, com promessas de facilitar o diagnóstico das lesões mamárias ${ }^{6}$.

Ainda com a intenção de melhorar a acurácia da USG para lesões sólidas, vários tipos de "indices de avaliação ecográfica" vêm sendo testados. Michelin e Levy ${ }^{8}$ dividem as lesões sólidas em quatro grupos, de acordo com a probabilidade de malignidade e com o tipo e número de características suspeitas: grupo E4, com 90\% de malignidade (4 sinais cardinais ou 3 sinais cardinais mais 2 sinais secundários); grupo E3, com $68,6 \%$ ( 3 sinais cardinais ou 2 cardinais mais 2 secundários); grupo $\mathrm{E} 2$, com $56,9 \%$ de tumores malignos ( 2 sinais cardinais ou 1 cardinal mais 2 secundários); grupo E1, com 40,5\% (1 sinal cardinal ou 2 sinais secundários).

Esses escores poderão ajudar muito no aprimoramento da acurácia ultra-sonográfica, entretanto, é necessário que haja, inicialmente, maior discussão e a tentativa de formar um consenso sobre quais são as características sonográficas mais relevantes, menos subjetivas e mais 
reprodutiveis, para então elaborar uma pontuação de simples compreensão, fácil aprendizado e que possa ser usada por todos os ultra-sonografistas nas diversas partes do mundo. Discute-se atualmente a criação de um sistema semelhante ao conhecido BI-RADS, utilizado para o diagnóstico mamográfico, que possa ser aplicado à USG ${ }^{15}$.

Concluímos assim que a ultra-sonografia é método que pode ser de grande auxílio na diferenciação entre os nódulos sólidos benignos e malignos e que algumas características sonográficas, quando presentes (sombra acústica posterior, contornos irregulares, ecos internos heterogêneos e diâmetro ântero-posterior maior do que o láterolateral), têm maior probabilidade de estarem associadas ao diagnóstico de câncer.

\section{ABSTRACT}

Purpose: to evaluate, in a prospective way, the importance of ultrasound features of solid breast lesions in the differentiation between benign and malignant lumps.

Methods: one hundred and forty-two patients with solid breast lesions, from the Department of Gynecology and Obstetrics of the Federal University of Goias (Brazil), were included in the trial. All ultrasound examinations were performed by a training doctor, always supervised by an experienced professional. The characteristics of the lesions studied were: shape, retrotumoral echoes, internal echoes, oriented diameter, halo of bright echoes and Cooper ligaments. Each of the ultrasound features was compared to the results of the histological examination.

Results: among the 142 patients included in the trial, 90 (63\%) had their lesions excised, and 77 (86\%) had pathologic diagnoses of benign tumors and 13 (14\%) of malignant tumors. The following characteristics were statistically significant in the diagnosis of the breast cancer $\left(\chi^{2}\right)$ : masses with retrotumoral shadowing $(p=0.0001)$, irregular shape $(p=0.0007)$, heterogeneous internal echoes $(p=0.0015)$ and vertically oriented - taller than wide $(p<0.0001)$. The presence of halo of bright echoes anterior to the lump and the presence of wider Cooper ligaments were not related to the correct diagnosis of malignancy in this trial.

Conclusion: ultrasound is a diagnostic method that can help physicians between the differentiation of benign and malignant breast lumps. The presence of retrotumoral shadowing, irregular shape, heterogeneous internal echoes and vertical orientation - lesions taller than wide - were related to the pathologic diagnosis of breast malignancies.

KEY WORDS: Breast cancer. Diagnosis. Ultrasound.

\section{Referências}

1. Parkin DM. Global cancer statistics in the year 2000. Lancet Oncol 2001; 2:533-43.

2. Brasil. Ministério da Saúde. Instituto Nacional de Câncer - INCA. Estimativas da incidência e da mortalidade por câncer. Rio de Janeiro: INCA; 2001.

3. Jatoi I. Breast cancer screening. Am J Surg 1999; 177:518-24.

4. Callen PW. O exame ultra-sonográfico obstétrico. In: Callen PW, editor. Ultra-sonografia em Obstetrícia e Ginecologia. $1^{\mathrm{a}}$ ed. Rio de Janeiro: Guanabara Koogan; 1996. p.3.

5. Sickles EA, Filly RA, Callen PW. Breast cancer detection with sonography and mammography: comparison using state of the art equipment. AJR Am J Roentgenol 1983; 140:843-5.

6. Rizzatto GJ. Towards a more sophisticated use of breast ultrasound. Eur Radiol 2001; 11: 2425-35.

7. Michelin J, Levy L. Patologia cística. In: Michelin J, Levy L, editores. Ultra-sonografia da Mama diagnóstica e intervencionista. $1^{\text {a }}$ ed. Rio de Janeiro: MEDSI; 2001. p.23-40.

8. Michelin J, Levy L. Tumores malignos. In: Michelin J, Levy L, editores. Ultra-sonografia da mama diagnóstica e intervencionista. $1^{\text {a }}$ ed. Rio de Janeiro: MEDSI; 2001. p.67-125.

9. Stavros AT, Thickman D, Rapp CL, Dennis MA, Parker SH, Sisney GA. Solid breast nodules: use of sonography to distinguish between benign and malignant lesions. Radiology 1995; 196:122-34.

10. Huber S, Danes J, Zuna I, Teubner J, Medl M, Delorme S. Relevance of sonographic B-mode criteria and computer-aided ultrasonic tissue characterization in differential/diagnosis of solid breast masses. Ultrasound Med Biol, 2000; 26:1243-52.

11. Durfee SM, Selland DL, Smith DN, Lester SC, Kaelin CM, Meyer JE. Sonographic evaluation of clinically palpable breast cancers invisible on mammography. Breast J 2000; 6:247-51.

12. Kitaoka F, Sakai H, Kuroda Y, et al. Internal echo histogram examination has a role in distinguishing malignant tumors from benign masses in the breast. Clin Imaging 2001; 25:151-3.

13. Rosen EL, Soo MS. Tissue harmonic imaging sonography of breast lesions: improved margin analysis, conspicuity, and image quality compared to conventional ultrasound. Clin Imaging 2001; 25:379-84.

14. Reinikainen H, Rissanen T, Paivansalo M, Paakko E, Jauhiainen J, Suramo I. B-mode, power Doppler and contrast-enhanced power Doppler ultrasonography in the diagnosis of breast tumors. Acta Radiol 2001; 42:106-13.

15. Mendelson EB, Berg WA, Merritt CR. Toward a standardized breast ultrasound lexicon, BI-RADS: ultrasound. Semin Roentgenol 2001; 36:217-25. 